\title{
Development and implementation of a tailored health promoting school in The Netherlands: Lessons learned
}

\author{
Busch, Vincent $\square \Delta$ \\ University Medical Center Utrecht, The Netherlands (v.busch@umcutrecht.nl) \\ De Leeuw, Johannes Rob Josephus \\ University Medical Center Utrecht, The Netherlands (j.r.j.deleeuw@umcutrecht.nl) \\ Schrijvers, Augustinus Jacobus Petrus \\ University Medical Center Utrecht, The Netherlands (mail@ guusschrijvers.nl)
}

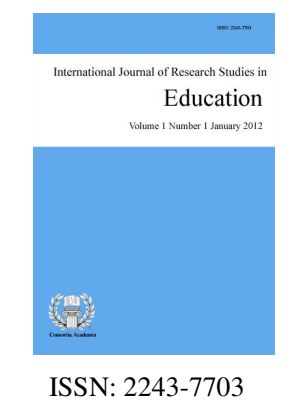
Online ISSN: 2243-7711

OPEN ACCESS \begin{tabular}{lll}
$\begin{array}{l}\text { Received: } 7 \text { November } 2013 \\
\text { Available Online: } 28 \text { November } 2013\end{array}$ & $\begin{array}{l}\text { Revised: } 12 \text { November } 2013 \\
\text { DOI: } 10.5861 / \text { ijrse.2013.613 }\end{array}$ & Accepted: 27 November 2013 \\
\hline
\end{tabular}

Available Online: 28 November 2013

\begin{abstract}
This paper presents the lessons learned from the design and implementation of a whole school Health Promoting School (HPS) pilot on a high school in The Netherlands. This pilot aims to improve a range of health behaviours in adolescents via the Whole School Approach of Health Promoting Schools framework of the WHO-supported Schools for Health in Europe initiative (SHE). Eleven semi-structured interviews were held with key stakeholders in the intervention's design and implementation. Results showed that becoming a HPS should be considered a comprehensive curriculum change that requires significant organizational investments. By integrating the intervention instead of implementing it "as is" into school's existing infrastructure the additional burden to the curriculum was minimized; this was important for intervention relevance and it strengthens feelings of intervention ownership and motivation among teachers. Also, implementation should be led by a steering group of professionals from health sciences and education as well as parents, students and teachers from the school to combine knowledge on practical feasibility and evidence based practices. Teachers should be further educated to increase competence in their new role. Lastly, a central coordinator with proper personal competencies and power to get things done is necessary to steer these developments. Since not all schools are able to make the necessary investments, successfully becoming a HPS is not feasible for just any school at any point in time; it has to be considered a well-planned comprehensive system change. Schools with competing problems such as school violence or organizational struggles should postpone HPS developments.
\end{abstract}

Keywords: Health Promoting School; intervention; behavior; implementation; adolescents 


\section{Development and implementation of a tailored health promoting school in The Netherlands: Lessons learned}

\section{Introduction}

Since children spend most of their time at school, it forms the ideal place for health promotion (World Health Organization 1986, 1997; World Health Organization, UNESCO \& UNICEF 1992). Therefore, the Schools for Health in Europe (SHE) initiative has been developed to promote the active crossover of education and health to create more effective, sustainable and feasible health promotion initiatives targeting children and adolescents: the Health Promoting School (HPS) (see Figure 1) (Barnekow-Rasmussen \& Rivett, 2000). SHE advocates this by promoting the integration of health promotion and education both into school and into the social environment of children simultaneously via five main principles of the guiding framework of the whole school approach (Barnekow-Rasmussen \& Rivett, 2000). These five principles entail 1- building healthy public policy; 2- create supportive environments; 3- strengthening community action; 4- developing personal skills and 5- re-orientating health care services towards prevention of illness and promotion of health.

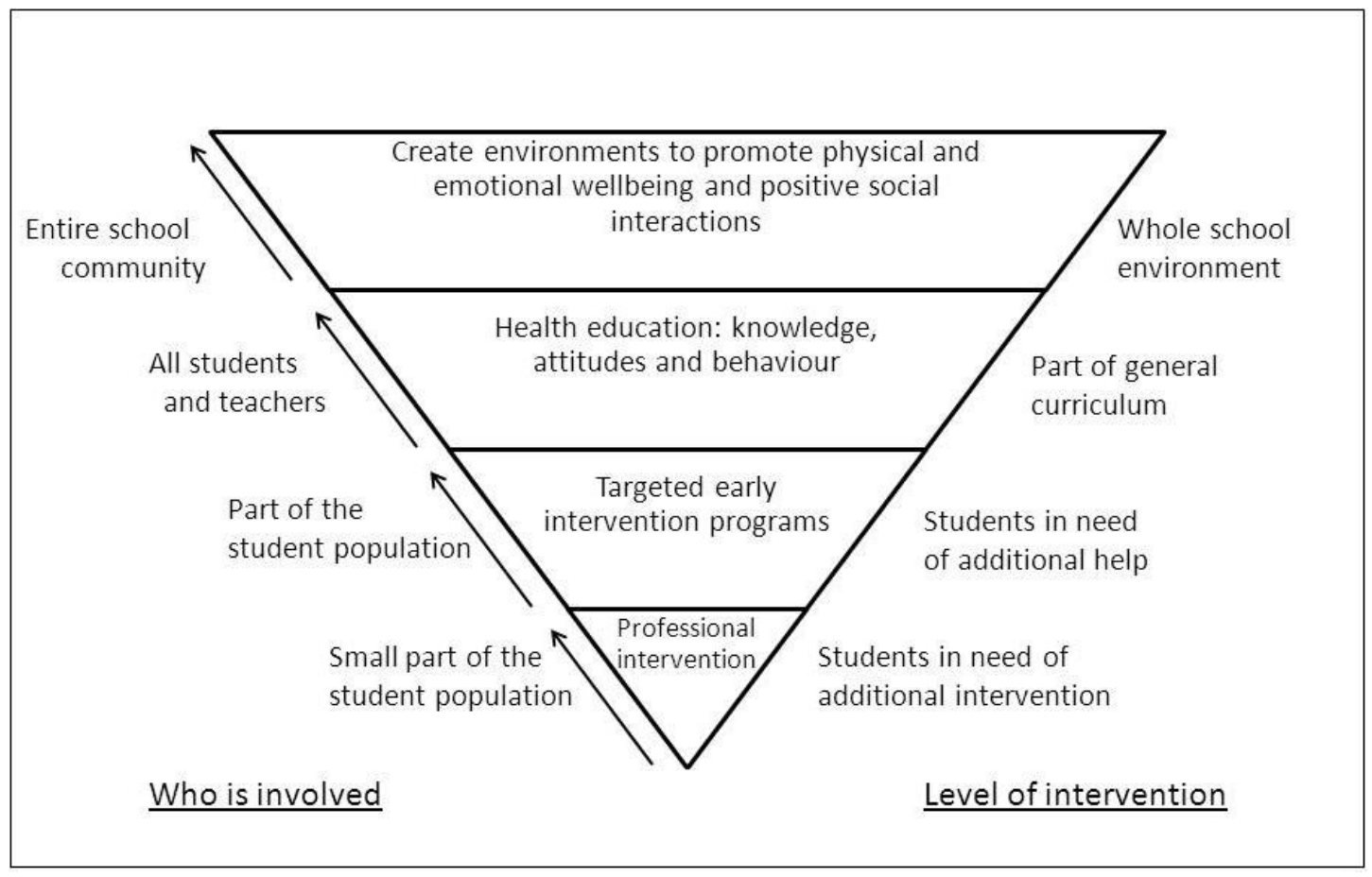

Figure 1. World Health Organization model of the whole school approach, adapted from Wynn, Cahill, Holdsworth, Rowling, and Carson (2000) from Hendren, Birrell, Weissen, and Orley (1994)

In addition, accumulating evidence shows many health behaviors in adolescents to cluster (De Bruijn \& Van Den Putte, 2009; De Vries et al., 2008; Peters et al., 2009; Van Nieuwenhuijzen et al., 2009). Increasingly studies show such clustered behaviors to be most effectively tackled via interventions that address these behaviors simultaneously via a multi-behavioral approach instead of by single-behavior initiatives (Burke et al., 1997; Ottevaere et al., 2011). This could lead to even more comprehensive future HPS initiatives.

As previous research illustrated, intervening via a whole school approach is quite demanding for a school in terms of planning and organization (Gugglberger \& Dür, 2011). Parsons and Stears added to this with their summary of specific goals and aims needed to properly fine-tune comprehensive HPS interventions (Parsons \& Stears, 2002). To date only a modest number of studies described lessons learned on designing and implementing 
Development and implementation of a tailored health promoting school in The Netherlands: Lessons learned

HPS initiatives operationalized via SHE's whole school approach from a practical education perspective (Beets et al., 2008; Bonell et al., 2010; Deschesnes, Martin, \& Adele Jomphe-Hill, 2003; Flaspohler, Meehan, Maras, \& Keller, 2012; Klostermann, Perry, \& Britto, 2000; MacDonald \& Green, 2001; Piper, King, \& Moberg, 1993; Powers, Bowen, \& Bowen, 2010).

This paper presents the lessons learned from the development and implementation of a whole-school HPS pilot intervention in The Netherlands (the Utrecht Healthy School Pilot (UHSP)). Special focus will be placed on the crossover of the domains of health and education in these processes, since these are believed to be of significant value to future initiatives, and to have been problematic according to evaluations of past HPS initiatives (MacDonald \& Green, 2001; Piper, King \& Moberg, 1993; Powers, Bowen \& Bowen, 2010).

\section{Methodology}

Semi-structured, in-depth interviews (structured by means of a preset topic list) were performed with key stakeholders in the development and implementation processes of the UHSP $(\mathrm{N}=11)$. The whole school approach' main characteristics served as source for the interviews' sensitizing topics or themes to structure the interviews. These interview themes were summarized and elaborated upon in Table I. The order in which the topics were addressed was not preset, and no response options were provided. This process of interviewing was standardized to increase data reliability.

The interviewees were representatives of the school's teachers, school policy makers, school board, parents and public health practice and research professionals. These represent stakeholders from most parties that worked together to design and implement the UHSP. Due to their relatively large role in the intervention's implementation of the stakeholder groups of teachers and school members, multiple interviews were performed among them. The variety of perspectives among the interviewees added to the validity of the data and provided confidence that data saturation took place and all major lessons were identified. Qualitative analysis program WinMax 97 Professional (Wyse, 1997) was used to analyze the interviews. In addition, policy- and research documents, related to the UHSP, were analyzed and integrated into the lessons learned.

\section{Table I}

Main questions from the interviews with the Utrecht Healthy School Pilot multidisciplinary steering committee

\begin{tabular}{l}
\hline \\
\hline 1 \\
The origination and set-up of the steering group. \\
Examples of questions: What led to the school's urge to get involved with health promoting school efforts? How those \\
involved did decided to compose the steering committee? \\
The coordinating efforts to develop the HPSP. \\
Example of questions: What did the novel education add/change with regard to the existing curriculum? How the novel \\
educational content was integrated into the existing curriculum, and how were these efforts coordinated at school? What was \\
done so that both teachers and students were enthusiastic about the UHSP and implementation went smooth? \\
The function and composition of the steering group in the initial Utrecht Healthy School Pilot development. \\
Examples of questions: How were the different members of the steering committee involved with the UHSP? What were their \\
fields of expertise and what did each participant add? How often did you meet? How were decisions made? \\
The possibilities for teacher input during the implementation phase. \\
Examples of questions: Were teachers actively involved in the steering group's process of designing the UHSP and if so, \\
how? How was their input processed? \\
The undertaken efforts to institutionalize the HPSP into the school to ensure the program's durability. \\
Examples of questions: How was the future stability of the UHSP "ensured"? How, if so, did the steering group try to let the \\
UHSP be more than a temporary "project"? \\
The lessons that future schools can deduct from the experiences on this pilot school. \\
Examples of questions: What would future schools need to learn from the UHSP when wanting to be involved with health \\
promoting school efforts? What would schools need to ensure in terms of school infrastructure to optimize their chances of \\
successful implementation and institutionalization?
\end{tabular}

\section{Results}

\subsection{The Utrecht Healthy School pilot: the whole school approach in practice}

The UHSP is a HPS initiative that aimed to promote health and healthy behavior on a range of the most 
predominant health-related behaviors in Western adolescents (World Health Organization, 1998). It was operationalized according to SHE's whole school approach with the added aspect of tailoring the intervention to the school's needs in form and content.

The UHSP changed the curriculum by providing students with two weekly hours of health education. These were integrated in the first three years of the curriculum. The educational content consisted of evidence based components that underwent a (minor) degree of tailoring to be optimally relevant and feasible for the school to implement. It was implemented as a complement to the existing curriculum, instead of replacing original curricular methods/structures, thereby minimizing the additional burden. For further details we refer readers to the UHS website (Website Gezond Maakt Slim, 2009).

\subsection{Lesson 1: Tailor HPS interventions in content and format.}

The UHSP was tailored in two ways to facilitate relevance and implementation. Firstly, the content was tailored: each year a self-report survey (based on the WHO's HBSC survey (World Health Organization, 1998)) was completed by the school's students. These results were used by the school to prioritize relevant topics of the UHSP. This decision was based on the relative prevalence of certain unhealthy behaviors and health problems/situations. This ensured the school specific relevance of the UHSP's content to them.

Secondly, the educational format was tailored: instead of implementing standardized evidence based methods/modules and treating them as "one size fits all", the intervention modules underwent (minor) school tailoring to fit into the existing curriculum.

The interviewees felt it to be a strength of their approach compared to other school-based interventions that their efforts were "demand-driven", i.e. it tackled the topics that were relevant to their school in a fashion that suited their school instead of replacing pre-existing policies and curricular structures by implementing a standardized regardless of school context.

"After agreement on the educational content and goals, the practical details were worked out by the teaching staff in collaboration with the steering committee in order to integrate the content into the existing curriculum without altering the core of the novel modules" [Teacher]

\subsection{Lesson 2: Design and implementation should be led by a steering group of health professionals, educational}

professionals and representatives of the teachers, parents and students.

The UHSP was designed and implemented by a steering group of representatives of the school's parents, students, teaching staff, school board and of health researchers and professionals. This allowed the steering group to oversee the intervention's school-specific practical relevance and feasibility while preserving its evidence based nature. The interviewees stated that researchers too often only focus on what has been shown effective without affiliation for school specific appropriateness and feasibility, while schools often thrive too much on good intentions without regard for evidence based practices. Therefore, both academic experts as well as professionals from the school worked together to create a feasible and effective intervention.

This mix of perspectives was said to have enabled them to better understand and motivate teachers to be part of the HPS. They recognized the value for schools of societal recognition. For example, media attention showed to be significantly motivating for teachers.

"Schools love good publicity. They enjoy the appreciation of their work enormously. We did not fully anticipate how strong an effect the involvement of all those "important organizations" such as the public health authorities or a University Medical Center would have, but it turned out to be very stimulating; a factor surely not to be underestimated when endeavoring in something like this in the future at other schools" [Steering group member] 
Development and implementation of a tailored health promoting school in The Netherlands: Lessons learned

Another example of this was shown by the steering group's focus on identifying mutual benefits for both education and health. While most HPS efforts predominantly focus on health benefits the UHSP was also aimed to improve educational outcomes, e.g. improving school grades or reducing absenteeism. This was hypothesized to result in more motivated teachers and eventually more sustainable initiatives.

\subsection{Lesson 3: Centralize coordination and communication efforts via one main HPS coordinator.}

"The teachers, the real implementers, they need to know where to go to and be assisted quickly when they have questions or issues (...) their motivation and confidence in the UHSP are vital for its success" [School board member]

The interviewees stated that to ensure smooth implementation and clarity of communication with regard to tasks, expectations and responsibilities for the teaching staff a central coordinating figure is needed. Besides being a committed motivator he/she requires in-depth knowledge of, and familiarity with, the UHSP topics. However, since personal competencies were often stated to be insufficient to achieve the desired change, this coordinator also must be facilitated with the executive power to make decisions and to force compliance, if needed, to get things done.

"getting a young biology teacher with only a great deal of enthusiasm and commitment is just not enough. A proper HPS coordinator also needs to be an in-school authority figure, to have in-depth subject knowledge and he/she is to be facilitated with sufficient resources by the school board and-policy makers. This was one of our most important lessons and it was, unfortunately, learned the hard way" [Steering group member]

3.5 Lesson 4: Involve parents, teachers and neighborhood to achieve a broader social embedding of the HPS.

The steering group reached out to the parents and neighborhood/community to ensure relevance and to help embed the HPS in the students' social environment. The interviewees stated that these efforts were partly successful.

Involving parents was found to be fruitful; the school's parent council for example aided in shaping the intervention as part of the steering group. The interviewees stated that such collaborations are too scarce, while schools could use the human resources to make such comprehensive interventions feasible and many parents are often enthusiastic about being involved in school affairs.

Conversely, school efforts to involve the neighborhood via local shop owners were less successful; they indicated that to stop selling e.g. cigarettes and soda to students would harm their livelihood.

“... and since you have no leverage to force compliance in such situations, we just had to deal with that" [HPS Coordinator]

Interviewees stated that new subsidy structures or innovations seem essential in order to progress.

Furthermore, teachers were also involved outside of the class room to serve as role models with their behavior. This was part of serious debate. Some felt it was a natural part of their role as teachers:

"just as I feel it is ridiculous to have doctors and nurses smoking just outside the hospital I feel that way about teachers smoking on a school yard (...) The credibility of the sender of a preventive health promotion message such as this is almost just as crucial as the content of the message." [Steering group member]

However, others felt it invaded their privacy e.g. to be restricted where to smoke or what not to eat at school. Most interviewees concluded that this issue should not be a priority during initial implementation, but rather of a follow-up development. They stated it will lead to less motivated teachers, which cannot be afforded in the early, 
fragile developmental stages.

Lastly, partnerships were formed with public health promotion and research organizations to ensure the use of evidence based (or best practices) methods. It was said that without such help it would be difficult to assure such quality, since schools often lack the time and knowledge to design such materials themselves.

\subsection{Lesson 5: Teach the teachers in order to ensure health education quality}

Given their relative unfamiliarity with several UHSP topics, school organized in-service trainings for teachers to develop the necessary competencies and confidence to function in their new work setting.

"Teachers were structurally offered in-service trainings to ensure that they were and felt competent to teach the new lessons. It is important that this is not something to improvise along the way; this needs to be planned and facilitated carefully. (...) To not do this will impair educational quality and reduce teacher motivation" [School board member]

Teachers generally had a positive attitude towards these in-service trainings and appreciated the topic-specific knowledge and to be taught how to integrate these topics in class. The UHSP-coordinator and the steering group spent a full year of planning, organizing and developing the totality of UHSP efforts and a significant part of this constituted these in-service trainings.

\subsection{Lesson 6: Health Promoting Schools: not for every school at any given time}

Several interviewees stated that not every school can afford to undertake a comprehensive investment as becoming a HPS at any given moment.

"For something like this to be feasible it is to be treated like a curriculum change, not a project" [Teacher]

Certain circumstances were stated to be prerequisites for innovations of this kind to be feasible. When dealing with more basic issues, such as school violence, organizational mergers or financial struggles, improving students' health behaviors will not be a priority. Therefore, the steering group pressed the issue that timing is a very important aspect with regard to the feasibility and implementation success of HPS innovations. Schools need to be in a phase of advanced development, instead of dealing with basic organizational and/or survival issues, to be able and willing to spend time and resources to becoming a healthy school. Only then will such developments be granted priority and be practically feasible.

\section{Discussion}

Several lessons were learned about the processes of designing and implementing a whole school HPS. In summary, these entailed that schools should view becoming a HPS as a comprehensive system change, not a project done alongside the regular curricular activities. To become a HPS means doing significant organizational investments such as educating the teaching staff and creating a steering group with experts from academics as well as teachers, students and parents from school. When such organizational infrastructures are taken care of, schools should properly tailor new educational materials in form and content to suit their particular school and student population and these developments should ideally be led by one central HPS coordinator. For purpose of discussion these lessons are embedded in, and compared to, a broader international HPS-developmental context.

\subsection{Lesson 1: Tailor HPS interventions in both content and form.}

It was stated that tailoring of the intervention should make for a more feasible and relevant HPS. This is hardly a novel aspect in public health science or in education (Campbell et al., 2000; Campbell et al., 2007; Pawson, Greenhalgh, Harvey, \& Walshe, 2005). However, in practice too often standardized interventions are 
Development and implementation of a tailored health promoting school in The Netherlands: Lessons learned

implemented without regard for context, while (minor) tailoring might result in more feasible implementation processes, more appropriate practices and less costly initiatives (Simovska, 2007). Also, teachers are more likely to experience more psychological ownership and responsibility which aids proper implementation (Tossavainen, Turunen \& Vertio, 2002). Flaspohler and colleagues further elaborated on this tailoring process:

"key ingredient to an effective prevention support system is the emphasis on best practice process over best practice program (...) "best practice process" refers to a systematic decision-making process and set of strategies that can be used to drive implementation of evidence-based practices. That is, a best practice process offers a guide for how evidence-based practices should be implemented rather than what or which evidence-based practices should be implemented." (Flaspohler et al., 2012, p. 440).

Since schools have limited time and room to integrate health education and promotion into their curriculum, they should prioritize topics to be tackled. Therefore, a second tailoring aspect was integrated regarding which health-related topics to be tackled. These were fine-tuned to the student population, ensuring that the topics addressed were actually relevant for them. This also likely resulted in more appropriate practices and stronger feelings of psychological ownership than targeting a preset collection of topics.

The UHSP's comprehensive, school-tailored, multi-behavioral approach is increasingly seen as a proper approach to HPS design (Flaspohler et al., 2012; Geddie \& Hobin, 2011; Patton, Bond, Butler, \& Glover, 2003) with well-known examples such the Gatehouse Project (Patton et al., 2003) and the Irish Mind Out project (Byrne, Barry, NicGabhainn, \& Newell, 2001). However, this approach still leads to significant practical roadblocks such as in a recent Russian HPS case study in which the schools generally did not take on such a comprehensive approach. This was mostly due to their vision of to what extent certain health promotion tasks are still within the scope of what a school should tackle (Weare, 2001). Including topics such as psychosocial health, bullying or internet use was not seen a task for school, but rather something that parents and students' social environment should pay attention to. In this still lays a challenge in shaping the perceptions of what a HPS is among teachers and schools.

\subsection{Lesson 2: Design and implementation should be led by a steering group of health professionals, educational professionals and representatives of the teachers, parents and students}

The value of integrating a combination of backgrounds and competencies in the design and implementation process as done in the UHSP was also recognized in previous research (Flaspohler et al., 2012; Hansen \& McNeal, 1999; Wold \& Samdal, 2012):

"There is a lack of effective interactions between schools and the health sector. (...) Inadequate flow of information and experiences about Health Promoting Schools between schools and between schools and health sector (Anderson, 2005)

Several positive aspects resulted from this multidisciplinary, participatory approach. Firstly, it made school tailoring of the intervention more feasible. Hereby the implementation took place without replacing existing initiatives, thereby strengthening feelings of ownership among teachers and parents (Baer \& Brown, 2012; Lee, Tsang, Lee, To, \& Kwan, 2001).

It also led to the realization that just assuming that teachers and parents were intrinsically motivated enough to undertake such a comprehensive curriculum would be too naïve. Therefore, a research aspect was added to study whether students' school achievements could be positively influenced by healthier behavior. This was used to convince teachers that the HPS was not "merely another health project", but something that aims to benefit both education as well as health outcomes. As stated by St Leger (St Leger, 1999), and extensively advocated by Flay later (Flay, 2002), HPS's should aim to make better schools (not health centers) that improve youngsters' health. The association with academic performance therefore seemed vital to take up as one of the intervention's 
Busch, V., De Leeuw, J. R. J., \& Schrijvers, A. J. P.

goals to get teachers enthusiastic about the HPS.

This participatory approach, comparable to Figure 2, offers promising opportunities. It has even been stated crucial in order to create a suitable, relevant and tailored HPS (Byrne et al., 2001; Patton et al., 2003; Tossavainen, Turunen \& Vertio, 2002). However, little is known on how to structurally involve, especially, students and parents in such developments. They are traditionally not familiar with such an active participatory approach, as illustrated in a Swedish HPS case study:

"Some pupils are dubious about participation and about taking more responsibility. It is much easier and more secure when the teacher lectures and takes all the responsibility and makes all of the decisions" (Nilson, 2003, p. 260)

Fairly equivalent arguments were made with respect to involving and giving teachers and parents more responsibilities in some processes. In this might play an important lesson for schools with HPS ambitions, namely to proactively involve students and parents earlier in the development process and share decision making and responsibilities.

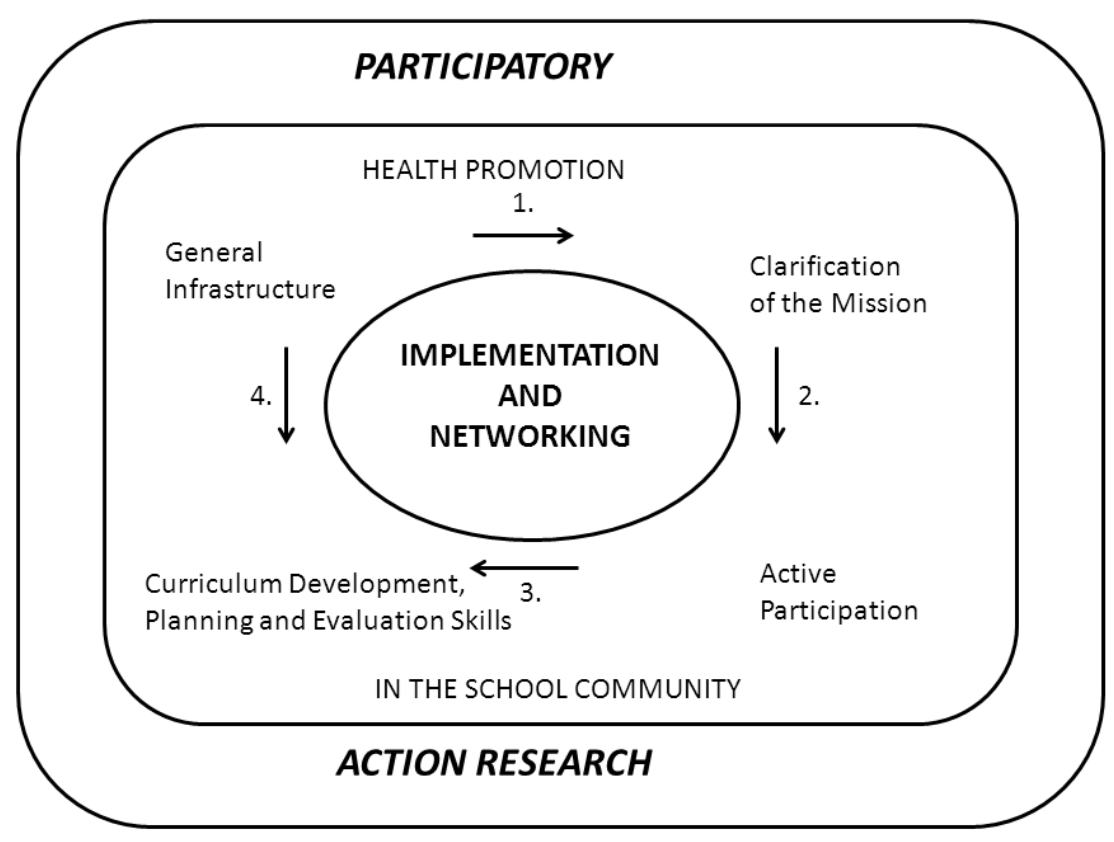

Figure 2: The Model of Health Promotion in the Finnish ENHPS Schools (Tossavainen, Turunen, \& Vertio, 2002)

\subsection{Lesson 3: Centralize coordination and communication efforts via one main HPS coordinator.}

The central communication and organization to steer implementation was also deemed important in previous studies (O'Brien et al., 2010; Patton et al., 2003; Piper, King \& Moberg, 1993; Wold \& Samdal, 2012). O’Brien et al. for example demonstrated the importance of having a central HPS coordinator at the school to strategically implement enforce and coordinate new HPS policies in their study of Maine's Coordinated School Health Program (CSHP) (O'Brien et al., 2010). An important part of having a HPS coordinator for this purpose seems to be that someone has this as a main task to do instead of it being something that a teacher does aside from his/her "real" job. This was somewhat easier to achieve in the CSHP, because there the schools hired someone especially for the purpose of being a HPS coordinator. However, many schools will not have the financial room for this, which makes it important that the school board appoints someone with the proper personal competencies, as well as granting him/her with the executive power to get things done. In other studies fairly comparable lessons were presented, providing confidence in these practical lessons and advices (Patton et al., 2003; Piper, 
Development and implementation of a tailored health promoting school in The Netherlands: Lessons learned

King \& Moberg, 1993; Wold \& Samdal, 2012).

4.4 Lesson 4: Involve parents, teachers and neighborhood to achieve a broader social embedding of the HPS.

Schools, by themselves, cannot, and should not be expected to, address the nation's most serious health and social problems (Kolbe, Collins \& Cortese, 1997). To achieve this, collaborative relationships with the community should be initiated, and partners should be systematically involved (Hoyle, Samek and Valois, 2008). Although the (potential) value of this collaborative approach was stated in the current study and also in other literature, practical roadblocks in the execution often lead to mixed experiences in terms of its feasibility (Barnekow-Rasmussen, 2005; Clift \& Bruun Jensen, 2005; Fagen \& Flay, 2009; Flay, 2000; Flay, 2002; Lee et al., 2001; Mukoma \& Flisher, 2004; Wold \& Samdal, 2012; St Leger, 1999). Experiences with involving parents to design the intervention and aid in involving the home environment were positive in the UHSP. However, in this respect the UHSP presents a biased image, since here the HPS was a bottom up intervention that was initiated by the parents to demand that the school should spend more attention to structural health education. Therefore, the UHSP offers limited lessons on this topic.

Conversely, involving teachers as role models, as a HPS element known to be effective (Clift \& Bruun Jensen, 2005), turned out to be much more of a struggle. Some teachers felt that such involvement in the HPS was an obvious part of their role as teachers, while others felt it invaded their privacy when e.g. they were not allowed to smoke in the school yard during breaks. In order to keep the teachers motivated and invested in the new UHPS developments the steering group and HPS coordinator decided to put these plans on hold, so that it would not jeopardize the total process of becoming a HPS. Whether to integrate teachers' behavior within HPSs varies per school and/or region; no one clear perception or consensus seems to exist. In a Russian HPS example teachers were positive about changing their own behavior as part of the HPS initiative (Weare, 2002). Their encountered roadblocks were practical, e.g. too low wages to join fitness clubs or eat healthy, whereas in the Dutch UHSP roadblocks were more on principle. The need for more structural efforts, such as teacher in-service trainings, to change teachers' perceptions on the necessity of being role models in the HPS seem to be a general trend across countries throughout Europe. With it, it might become more accepted to include teachers and they will learn how to change their behavior in practice. However, on the question of how to achieve this, no consensus yet exists. Findings of the UHSP evaluation suggest that timing seems vital in this and that involving teachers as role models should be initiated when the remaining structural parts have been embedded in the school statures.

"To lift the HPS out of the school benches" via a neighborhood embedding turned out to be problematic in case of the UHSP; interests differed and shop owners perceived the HPS as a threat to their sales and livelihood. However, Turunen and colleagues stated that the issue is often more complex than merely unwilling surroundings that inhibit the practical embedding of HPSs within neighborhood communities and fruitful collaborations with external partners. An important aspect that also plays part is the awareness and knowledge of teachers to what a HPS constitutes and how this could be optimized in practice.

"Teachers appear to acknowledge the rhetoric, but see community partnerships more in terms of resource acquisition, such as visiting speakers and information kits than working collaboratively to improve the opportunities for pupils' health (...) the development of links with the community has received little attention in the ENHPS schools, for example, in England, and it is the most problematic area for progress." (Turunen, Tossavainen, \& Vertio, 2004, p. 424)

This was also confirmed in context of an American HPS study:

"see their relationship with parents as being one-sided; in other words, they want parents to support them in their educational role, whereas parents are more interested in carrying on a reciprocal relationship with teachers" (Deschesness, Marthe \& Jomphe-Hill, 2003, p. 391) 
Overall, much still remains to be learned with regard to the optimal practical workings of involving the environment in shaping a HPS:

"The current literature is anything but clear on how to make this partnership a reality." (Deschesnes, Marthe \& Jomphe-Hill, 2003, p. 391)

\subsection{Lesson 5: Teach the teachers in order to ensure health education quality}

It is important to realize that the real implementers of any school-based intervention are the teachers; it has to become their program (Lynach, Knight, Schofield, \& Paras, 1999; Piper, King, \& Moberg, 1993; St Leger, 1998). With the variety of added health-related topics within a new HPS curriculum it is not realistic to assume that teachers will naturally be (and feel) competent and confident enough to teach in a HPS setting. Teacher in-service trainings showed to be a welcome and needed addition to the teachers' competencies for them to be able to tackle these relatively unfamiliar topics in class. By providing teachers with appropriate competencies and understanding on what a HPS constitutes, the health education component will be professionalized (Lee et al., 2001; Wold \& Samdal, 2012; St Leger, 1998). This was also illustrated in HPS case study from Russia:

"It is important to understand that the health promoting school is not only medical, but includes psychological and emotional health. We previously thought it was about doctors and dentists. We now think it is more about self-esteem." (Weare, 2002)

Since schools have been known to lack the expertise, time and resources to take on such initiatives by themselves, they should actively seek out collaborations for this. Via the relatively strong ties of public health authorities and schools in The Netherlands the UHPS demonstrated a practically feasible approach to the organization of such teacher education efforts.

\subsection{Lesson 6: Health Promoting Schools: not for every school at any given time}

Schools should realize that becoming a HPS should not be seen as a mere "project", but rather as a curricular systems change with according consequences for professional practice and needed investments (e.g. in teacher competencies and curricular developments). Therefore, HPS initiatives as comprehensive as the UHSP are unlikely to succeed at just any school. A rough comparison to Maslow's Pyramid of self-development can be made: only when a school has no other, more basic problems to attend to, such as reorganizations, financial stress or prominent problems such as school violence, self-development innovations such as becoming a HPS should be undertaken (Maslow, 1943). It is therefore important for schools to adapt a long-term vision with regard to their development and carefully plan when to integrate such efforts. In another recent study Flaspohler and colleagues stated that certain schools that were deemed "ready" to become a HPS had a much better chance at succeeding at this and that such indicators should be used to decide whether a school at a given time would be wise to endeavor in a HPS development (Flaspohler et al., 2012). However, as Flaspohler also hypothesized

"working with the ready may have drawbacks. Strategies that focus on eliminating schools without sufficient preliminary readiness may lead to the allocation of resources outside the highest areas of need. Schools and communities with the highest need are likely to experience lower levels of initial capacity and readiness and may not be selected to participate. However, the limited research available on supporting implementation of evidence-based programs suggests that a minimum level of initial capacity must be present to assure successful uptake" (Flaspohler et al., 2012, p. 440).

Overall, schools seem best to initiate HPS developments once certain basic prerequisite conditions are met.

\subsection{Strengths and limitations}

A strong point of the current study is its qualitative methodology that allowed for an in-depth study of the 
Development and implementation of a tailored health promoting school in The Netherlands: Lessons learned

lessons learned from the most relevant, practical stakeholder perspectives in HPS development. This practical focus shaped these lessons to be optimally useful for schools and education professionals. Weak points in the current study were the relatively low ethnic diversity and high socioeconomic status on the pilot school; this may have resulted in a school environment in which innovative practices would be somewhat more feasible. Also, the lessons learned from involving parents might be biased to be too positive, since at the UHSP the parents were the ones demanding the school to pay more attention to structural health education. In more regular situations in high schools in The Netherlands, parents are less involved with daily school practices and it will be more difficult to get parents enthusiastic and committed to via a similar approach.

\section{Conclusion}

This study showed that it is feasible to integrate a comprehensive, whole-school intervention that targets a range of different health behaviors as a complement to the pre-existing curriculum and school infrastructure. For schools it is important to realize that this development entails a comprehensive system change, it is not a project. Becoming a HPS is a development that requires significant investments in terms of organization and commitment in order to tailor the educational content to fit the school in question specifically and to properly educate the teaching staff, so that they possess the proper competencies and confidence to function in their new role. Since not all schools are able to make these necessary investments, successfully becoming a HPS is not feasible for just any school at any point in time; it has to be considered a well-planned comprehensive investment. Schools with more pressing problems to attend to such as school violence, financial stress or management changes should not (yet) aim to become a HPS. Schools that wish to endeavor in becoming a HPS should take into account the lessons learned and experiences from our study.

\section{References:}

Anderson, A. (2005). Understanding school improvement and school effectiveness from a health promoting school perspective. Revista Electrónica Iberoamericana sobre Calidad, Eficacia y Cambio en Educación, 3(1), 282-296.

Baer, M., \& Brown, G. (2012). Blind in one eye: How psychological ownership of ideas affects the types of suggestions people adopt. Organisation Behavior \& Human Decision Processes, 118(1), 60-71. http://dx.doi.org/10.1016/j.obhdp.2012.01.003

Barnekow-Rasmussen, V. (2005). The European network of health promoting schools - from Iceland to Kyrgyzstan. Promotion \& Education, 12(3-4), 169-172. http://dx.doi.org/10.1177/10253823050120030120

Barnekow-Rasmussen, V., \& Rivett, D. (2000). The European network of health promoting schools: An alliance of health, education and democracy. Health Education, 100(2), 61-67. http://dx.doi.org/10.1108/09654280010312397

Beets, M. W., Flay B. R., Vuchinic, S., Acock, A. C., Li, K. K., \& Allred, C. (2008). School climate and teachers' beliefs and attitudes associated with implementation of the positive action program: A diffusion of innovations model. Prevention Science, 9(4), 264-275. http://dx.doi.org/10.1007/s11121-008-0100-2

Bonell, C., Sorhaindo, A., Strange, V., Wiggins, M., Allen, E., Fletcher, A., Oakley, A., Bond, L., Flay, B. R., Patton, G. C., \& Rhodes, T. (2010). A pilot whole-school intervention to improve school ethos and reduce substance use. Health Education, 110(4), 252-272. http://dx.doi.org/10.1108/09654281011052628

Burke, V., Milligan, R. A., Beilin, L. J., Dunbar, D., Spencer, M., Balde, E., \& Gracey, M. P. (1997). Clustering of Health-Related Behaviors among 18-Year-Old Australians. Preventive Medicine, 26(5), 724-733. http://dx.doi.org/10.1006/pmed.1997.0198

Byrne, M., Barry, M., NicGabhainn, S., \& Newell, J. (2001). The development and evaluation of a mental health promotion programme for post-primary schools in Ireland, In: S. Clift, \& B. Bruun Jensen, (Eds.), The Health Promoting School: International Advances in Theory, Evaluation and Practice (pp. 383-409). 
Busch, V., De Leeuw, J. R. J., \& Schrijvers, A. J. P.

Copenhagen, Denmark: Danish University of Education Press.

Campbell, M., Fitzpatrick, R., Haines, A., Kinmonth, A. L., Sandercock, P., Spiegelhalter, D., \& Tyrer, P. (2000). Framework for design and evaluation of complex interventions to improve health. British Medical Journal, 321(7262), 684-696. http://dx.doi.org/10.1136/bmj.321.7262.694

Campbell, N. C., Murray, E., Darbyshire, J., Emery, J., Farmer, A., Griffiths, F., Guthrie, B., Lester, H., Wilson, P., \& Kinmonth, A. L. (2007). Designing and evaluating complex interventions to improve health care. British Medical Journal, 334(7591), 455-459. http://dx.doi.org/10.1136/bmj.39108.379965.BE

Clift, S., \& Bruun Jensen, B. (Eds.) (2005). The health promoting school: International advances in theory, evaluation and practice. Copenhagen, Denmark, Danish University of Education Press.

De Bruijn, G., \& Van Den Putte, B. (2009). Adolescent soft drink consumption, television viewing and habit strength. Investigating clustering effects in the theory of planned behaviour. Apetite, 53(1), 66-75. http://dx.doi.org/10.1016/j.appet.2009.05.008

De Vries, H., Van 't Riet, J., Spigt, M., Metsemakers, J., Van den Akker, M., Vermunt, J. K., \& Kremers, S. (2008) Clusters of lifestyle behaviors: Results from the Dutch SMILE study. Preventive Medicine, 46(3), 203-208. http://dx.doi.org/10.1016/j.ypmed.2007.08.005

Deschesnes, M., Martin, C., \& Jomphe-Hill, A. (2003). Comprehensive approaches to school health promotion: how to achieve broader implementation? Health Promotion International, 18, 387-396. http://dx.doi.org/10.1093/heapro/dag410

Fagen, M. C., \& Flay, B. R. (2009). Sustaining a School-Based Prevention Program. Health Education \& Behavior, 36(1), 9-23. http://dx.doi.org/10.1177/1090198106291376

Flaspohler, P. D., Meehan, C., Maras, M. A., \& Keller, K. E. (2012). Ready, willing, and able: Developing a support system to promote implementation of school-based prevention programs. American Journal of Community Psychology, 50, 428-444. http://dx.doi.org/10.1007/s10464-012-9520-z

Flay, B. R. (2000). Approaches to substance use prevention utilizing school curriculum plus social environmental change. Addictive Behaviors, 25, 861-885. http://dx.doi.org/10.1016/S0306-4603(00)00130-1

Flay, B. R. (2002). Positive youth development requires comprehensive health promotion programs. American Journal of Health Behavior, 26(6), 407-424. http://dx.doi.org/10.5993/AJHB.26.6.2

Geddie, D. L., \& Hobin, E. P. (2011). The battle river project: School division implementation of the health-promoting schools approach. Assessment for learning: Using student health and school capacity measures to inform action and direct policy in a local school district. Global Health Promotion, 18(1), 39-42. http://dx.doi.org/10.1177/1757975910393169

Gugglberger, L., \& Dür, W. (2011). Capacity building in and for health promoting schools: Results from a qualitative study. Health Policy, 101(1), 37-43. http://dx.doi.org/10.1016/j.healthpol.2010.08.019

Hansen, W., \& McNeal, R. (1999). Drug education practice: Results of an observational study. Health Education Research, 14(1), 85-97. http://dx.doi.org/10.1093/her/14.1.85

Hendren, R., Birrell Weisen, R., \& Orley, J. (1994). Mental health programs in schools. World Health Organization, Geneva, Switzerland.

Hoyle, T. B., Samek, B. B., \& Valois, R. F. (2008). Building capacity for the continuous improvement of health-promoting schools. Journal of School Health, 78(1), 1-8. http://dx.doi.org/10.1111/j.1746-1561.2007.00259.x

Klosterman, B. K., Perry, C. S., \& Britto, M. T. (2000). Quality improvement in a school health program: Results of a process evaluation. Evaluation and the Health Professions, 23(1), 91-106. http://dx.doi.org/10.1177/01632780022034507

Kolbe, L. J., Collins, J., Cortese, P. (1997). Building the capacity of schools to improve the health of the nation: a call for assistance from psychologists. The American Psychologist, 52(3), 256-265. http://dx.doi.org/10.1037/0003-066X.52.3.256

Lee, A., Tsang, K., Lee, S., To, C., \& Kwan, T. (2001). Challenges in the development of Health Promoting Schools: a review of Hong Kong innovations and initiatives. Health Education, 101(2), 83-89. http://dx.doi.org/10.1108/09654280110384829

Lynach, M., Knight, J., Schofield, M. J., \& Paras, L. (1999). Lessons learned from the hunter region health 
Development and implementation of a tailored health promoting school in The Netherlands: Lessons learned

promoting schools project in New South Wales, Australia. Journal of School Health, 69(6), 227-232. http://dx.doi.org/10.1111/j.1746-1561.1999.tb06394.x

MacDonald, M. A., \& Green, L. W. (2001). Reconciling concept and context: The dilemma of implementation in school-based health promotion. Health Education \& Behavior 28(6), 749-768. http://dx.doi.org/10.1177/109019810102800607

Maslow, A. H. (1943). A theory of human motivation, Psychological Review, 50(4), 370-396. http://dx.doi.org/10.1037/h0054346

Mũkoma, W., \& Flisher, A. J. (2004). Evaluations of health promoting schools: a review of nine studies. Health Promotion International, 19(3), 357-368. http://dx.doi.org/10.1093/heapro/dah309

Nilsson, L. (2003). The Shifting Relationship between Vocational and Higher Education in France and Germany: towards convergence? In S. Clift, \& B. Bruun Jensen, (Eds.), The health promoting school: International advances in theory, evaluation and practice (pp. 253-271). Copenhagen, Denmark: Danish University of Education Press.

O' Brien, L. M., Polacsek, M., MacDonald, P. B., Ellis, J., Berry, S., \& Martin, M. (2010). Impact of a school health coordinator intervention on health-related school policies and student behavior. Journal of School Health, 80(4), 176-185. http://dx.doi.org/10.1111/j.1746-1561.2009.00484.x

Ottevaere, C., Huybrechts, I., Benser, J., De Bourdeaudhuij, I., Cuenca-Garcia, M., Dallongeville, ... the HELENA Study Group. (2011). Clustering patterns of physical activity, sedentary and dietary behavior among European adolescents: The HELENA study, BMC Public Health, 11, 328. http://dx.doi.org/10.1186/1471-2458-11-328

Parsons, C., \& Stears, D. (2002). Evaluating health-promoting schools: Steps to success, Health Education, 102(1), 7-15. http://dx.doi.org/10.1108/09654280210412358

Patton, G., Bond, L., Butler, H., \& Glover, S. (2003). Changing schools, changing health? Design and implementation of the Gatehouse Project. Journal of Adolescent Health, 33(4), 231-239. http://dx.doi.org/10.1016/S1054-139X(03)00204-0

Pawson, R., Greenhalgh, T., Harvey, G., \& Walshe, K. (2005). Realist review - A new method of systematic review designed for complex policy interventions. Journal of Health Services Research \& Policy, 10(1), 21-34. http://dx.doi.org/10.1258/1355819054308530

Peters, L. W. H., Wiefferink, C. H., Hoekstra F., Buijs, G. J., ten Dam, G. T. M., \& Paulussen, T. G. W. M. (2009). A review of similarities between domain-specific determinants of four health behaviors among adolescents. Health Education Research, 24(2), 198-223. http://dx.doi.org/10.1093/her/cyn013

Piper, D. L., King, M. J., \& Moberg D. P. (1993). Implementing a middle school health promotion research project: Lessons our textbook didn't teach us. Evaluation \& Program Planning, 16(3), 171-180. http://dx.doi.org/10.1016/0149-7189(93)90001-O

Powers, J. D., Bowen, N. K., \& Bowen, G. L. (2010). Evidence-based programs in school settings: Barriers and recent advances. Journal of Evidence-Based Social Work, 7(4), 313-331. http://dx.doi.org/10.1080/15433710903256807

Simovska, V. (2007). The changing meanings of participation in school-based health education and health promotion: The participants' voices. Health Education Research, 22(6), 864-878. http://dx.doi.org/10.1093/her/cym023

St Leger, L. H. (1998). Australian teachers' understandings of the health promoting school concept and the implications for the development of school health. Health Promotion International, 13(3), 223-235. http://dx.doi.org/10.1093/heapro/13.3.223

St Leger, L. H. (1999). The opportunities and effectiveness of the health promoting primary school in improving child health: A review of the claims and evidence. Health Education Research, 14(1), 51-69. http://dx.doi.org/10.1093/her/14.1.51

Tossavainen, K., Turunen, H. \& Vertio, H. (2002). Collaboration as a learning research method in promotional and participatory action research in the Finnish ENHPS schools. In S. Clift, \& B. Bruun Jensen, (Eds.), The health promoting school: International advances in theory, evaluation and practice (pp. 271-291). Copenhagen, Denmark: Danish University of Education Press. 
Busch, V., De Leeuw, J. R. J., \& Schrijvers, A. J. P.

Turunen, H., Tossavainen, K., \& Vertio, H. (2004). How can critical incidents be used to describe health promotion in the Finnish European network of health promoting schools? Health Promotion International, 19(4), 419-427. http://dx.doi.org/10.1093/heapro/dah403

Van Nieuwenhuijzen, M,, Junger, M., Velderman, M. K., Wiefferink, K. H., Paulussen, T W. G. M., Hox, J., \& Reijneveld, S. A. (2009). Clustering of health-compromising behavior and delinquency in adolescents and adults in the Dutch population. Preventive Medicine, 48(6), 572-578. http://dx.doi.org/10.1016/j.ypmed.2009.04.008

Weare, K. (2002). What can we learn for the future development of the health promoting school idea from the experience of a projects in two regions in Russia? In S. Clift, \& B. Bruun Jensen, (Eds.), The health promoting school: International advances in theory, evaluation and practice (pp. 217-239). Copenhagen, Denmark: Danish University of Education Press.

Werkplaats Kindergemeenschap (2009). Website Gezond Maakt Slim. Retrieved November 10, 2013, from http://gezondeschool.wordpress.com/.

Wold, B., \& Samdal, O. (Eds) (2012). An ecological perspective on health promotion: Systems, settings and social processes. London: Bentham.

World Health Organization. (1986). Ottawa charter for health promotion. Geneva, Switzerland.

World Health Organization. (1997). Promoting health through schools. Report of a WHO Expert Committee on Comprehensive School Health Education and Promotion. WHO Technical Report Series 870, Geneva, Switzerland.

World Health Organization. (1998). Health Behaviour in School-aged Children a WHO cross-national survey (HBSC) research protocol for the 1997-98 study. Department of Community Health Sciences, University of Edinburgh, Edinburgh, Scotland.

World Health Organization, UNESCO \& UNICEF. (1992). Comprehensive school health education suggested guidelines for action. Geneva, Switzerland.

Wynn, J., Cahill, H., Holdsworth, R., Rowling, L. \& Carson, S. (2000). MindMatters, a whole-school approach promoting mental health and wellbeing, Australian and New Zealand Journal of Psychiatry, 34(4), 594-601. http://dx.doi.org/10.1080/j.1440-1614.2000.00748.x

Wyse, D. (1997). Grounded Theory and Winmax Pro. Presented at the British Educational Research Association Annual Conference 1997, University of York, York, United Kingdom. 